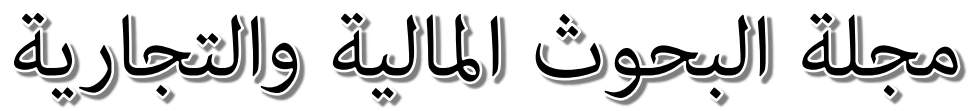

$$
\begin{aligned}
& \text { المجلد (21) - العدد الرابع - أكتوبر } 2020
\end{aligned}
$$

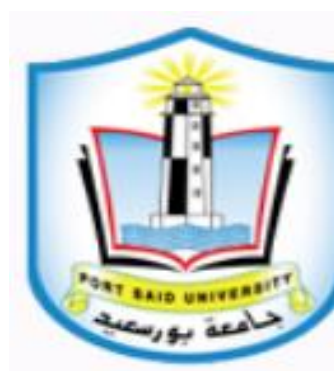
تطور العلاقات السعودية - الإيرانية وآثارها على القضية القلسطينية خلال الفترة من 2001 - 2016

Saudi Arabian - Iranian relations development and its impacts in Palestinian case from 2001 to 2016

$$
\begin{aligned}
& \text { الباحث/ محمد أحمد حسن أحمد } \\
& \text { مرشح للماجستير } \\
& \text { كلية التجارة- جامعة بورسعيد- قسم العلوم السياسية }
\end{aligned}
$$

رابط المجلة: / https://jsst.journals.ekb.eg 
مقدمة:

منذ العام 1928 أسست العلاقات السعودية - الإيرانية، فمرت بعدة مراحل منذ قيام حكم آل سعود وتزامنه مع تثكيل حكومة "رضا خان" الملكية في إيران، وتأثرت بما حدث في المنطقة

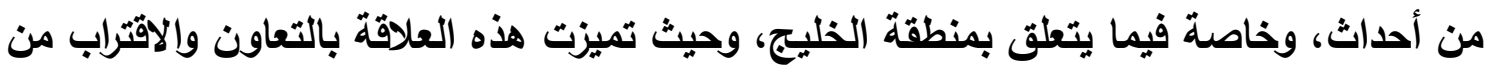

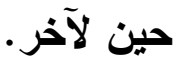

وأدى وقوع الثورة الإيرانية سنة 1979ونجاحها لمرحلة جديدة في العلاقات السعودية الإيرانية، حينما زعزعت الأوضاع في المنطقة واتسمت العلاقة بعدم التعاون والاستقرار بسبب مبدأ لأبها

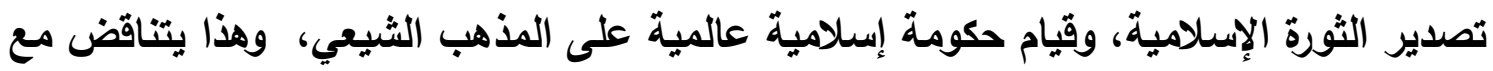

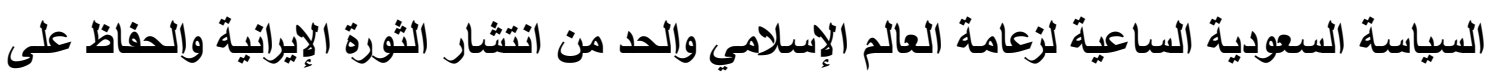

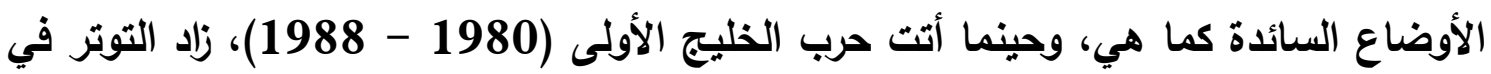
العلاقات بعد تعمد السعودية مساعدة العراق، على حساب إيران بدوافع قومية متوجسة من تصدير الثورة.

ويعد وفاة الخميني وتولي هاثمي رافسنجاني رئاسة إيران، تميزت فترة حكمه بمسيرة

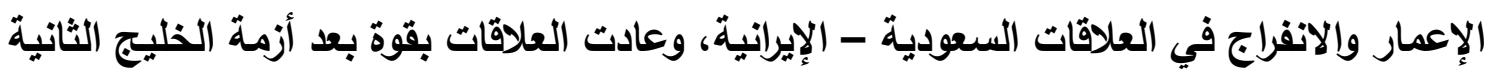
(حرب تحرير الكويت1990- 1991)، وكنلك مرحلة التعاون (1997 - 2005) فترة محمد

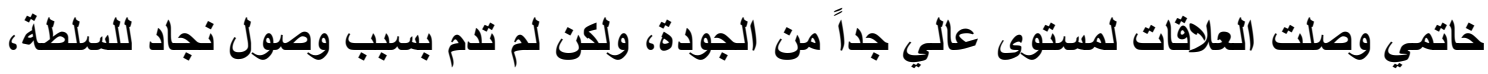
وتوتر العلاقات وحدث فتور بهات

وكان لأحداث 11 سبتمبر سنة 2001، ثم احتلال أفغانستان وغزو العراق تأثير كبير

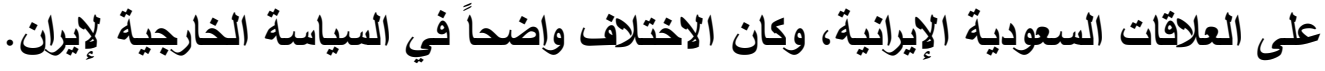
المبحث الأول: المحددات الداخلية للعلاقات السعودية الإيرانية. المبحث الثاني: المحددات الخارجية للعلاقات السعودية الإيرانية.. 
المبحث الأول: المحددات الاخلبـة للعلاقات الايرانية السعودية

أولا ايرلن: وتتأثر سياسة إيران الخارجية بعدد من العوامل الداخلية والتحى تؤثر فح_علاقاتها الخارجية أيضا ومن هذة العوامل:

$$
\text { 2- 1- العامل الجغرافى حيث الموقع والموضع. }
$$

الموقع: المساحة 1648195 كم2 وتقع ايران فى قارة أسيا ويحدها شمالا تركمانستان ويحرقزوين وتركيا وأزريبيجان وأرمينيا وجنويا وخليج فارس (العربى) ودول الخليج وشرقا أفغانستان وغريا العراق .

الحدود وإجمالهاء 5440كم2 وتطل ايران على الخليج العربى ومضيق هرمز ويحر قزوين وهذا الوضع الجيواستراتجى لعب دورا هاما ومحوريا للايران. التضاريس: حيث الجبال الوعرة وحوض عالى فى الوسط مع صحارى وجبال وسهول صغيرة متقطعة على إمتذاد الساحلين الموضع: السكان: ويتألف أساسا السكان من فرس وتاجيك ويسكنون العراق ومنطقة أصفهان وفارس وسيستان واللفة الرسمية للبلاد الفارسية وعدد السكان 68959931 (حسب تقديرات يوليو200) والأديان الاسلام ( الثيعة89\% والسنة10\% والزرادشتية واليهودية والمسيحية والبهائية 1\%

الموارد: مع تدفق النفط تثطورت طهان وأصبحت عاصمة حديثة تضاهى عواصم اليوم ويها صناعات كهريائية وصناعات السكر والاسمنت والسيارات والاسلة النووية الشخصبة القومبة والتغير الاجتماعى: ويرى علماء القرس أن أول نسبهم "كيومرث" وطبقاتهم الفشدانية والكياتية والاسغانية والساسانية وأولهم أردشر بن بابك والتكوين الاجتماعى الإيرانى يبدأ من عصور سحيقة فى القدم 2000 عام قبل الميلاد أقل تقدير مرورا بحضارات أخرى ثم دخولهم الاسبلام التطور السياسى: المجتمع الإيرانى معقد الاطراف بتركيبتة الاجتماعية والسياسية والنظام الايرانى جمهورى بعد ثورة 1979 بعد أن كان ملكيا وهناك العديا من مؤسسات الحكم وهى: مؤسسة المرشد: ويعتبرالولى الفقية أو المرشد الاعلى فى النظام السياسى الايرانى وهو أعلى من السلطات الثلاثة وسلطتة مطلقة وفقا للاستور وهو صانع القرار الاول ويسمو فوق كل الخلافات السياسية والمتغيرات الايديولوجية 
السلطة التنفيذية: حيث ريئس الدولة وهو أعلى سلطة بعد المرثد والمسؤل عن تنفيذ الاستور وله سلطة تعين الوزراء بعد موافقة مجلس الثورى وعزلهم وينتخب انتخاب مباشر من الثبب لمدة 4 سنوات ولدة دورتين وتحدد مهام عملة حسب المادة 113,133 من الدستور السلطة التشريعية: وتنقسم الى 1- مجلس الثورى الاسلامى ويتألف من 270 عضو أو يثمل مناطق ايران المختلفة وينسبة (150 (150 ألف نسمة ) 2- مجلس صيانة الدستور ومهمتة التأكيد على القرارات الصادرة عن مجلس الشورى من حيث المطابقة للأحكام الإسلامية والاستور السـلطة القضـائبة : وهى مسـتقلة تدافع عن الحقوق الفردية والإجتماعية وفق المادة 156 من الاستور مجلس الخبراع: ويضم 84 عضوا ومدتة 8سنوات ويتولى تعديل وإلغاء مواد من الاستور وإختيار

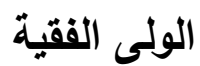
المجلس الأعلى للأمن القومى: ويتكون من رؤســــاء الســلطات الثلاثة وريئس أركان الجيش

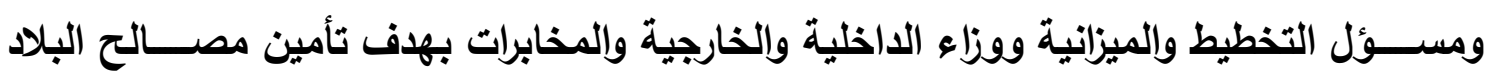
العليا مجلس تثخيص مصلحة النظام: ويشكل بأمر المرشد ويقرب وجهات النظر فى المسائل الخلافية بين مجلس صيانة الدستور ومجلس الثورى ويعين المرشد أعضاء المجلس حسب المادة 102 من الاستور الاحزاب الايرانية وتنقسم الى المحافظ وإلمعتدل :

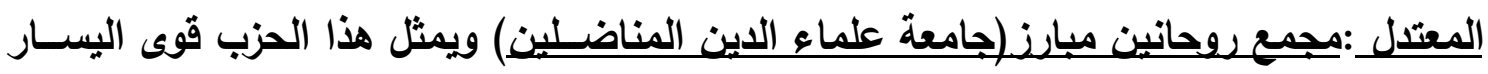
الاصلاحى الساعية للاصلاح وهم جزء من طلائع الثورة وولائهم للنظام وولاية الفقية

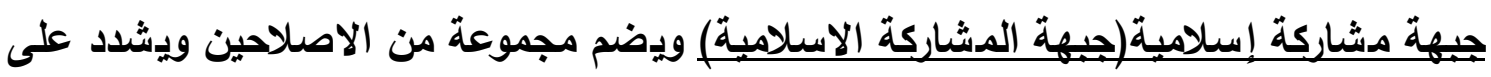
مفاهيم الحقوق الاستورية وإلحرية المدنية وحاكمية الثعب وسيادة القانون

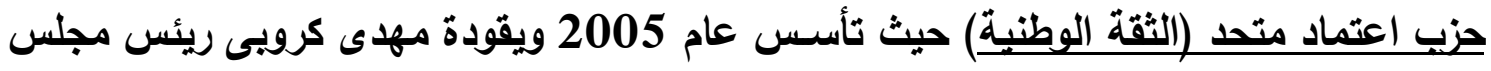

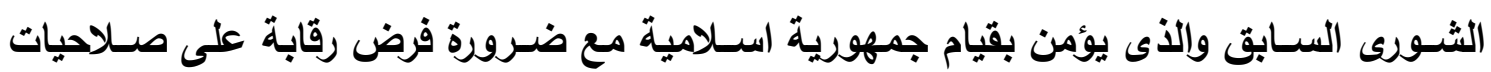

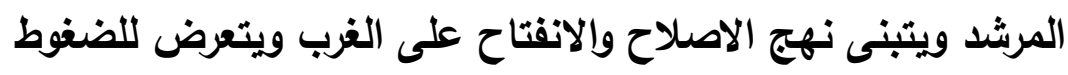


كوادر الاعمار والبناء (كاركوزلانان) : وتكونت هذة المجموعة قبل الانتخابات التشـريعية الخامسـة 1996 وكان رافسنجانى غطاء سياسى لها وتعمل على الانفتاح الاقتصـادى والتركيز على بناء ايران داخليا التيار المحافظ (المتشدد) : وتعد سيطرة المحافظين على الثورى فى إنتخابات 2004 الرئاسية بمثابة إحكام السيطرة على عملية صنع القزار فى ايران

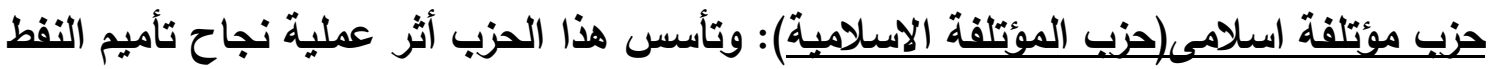
(1961 - 1963) حيث لعب دورا مهما فى نجاح الثورة ويؤيد ولاية الفقية ائتلاف تيران كلان (الاوفياء أو المؤثرون) :وهى المجموعة المسيطرة على الحكومة ويمثلها تيار

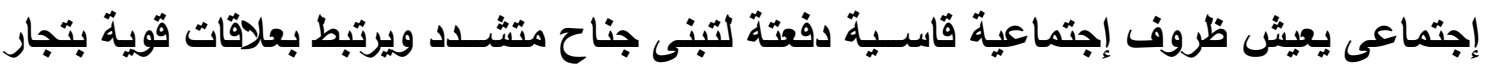
البازار ومنهم غالبية القوات المسلحة والحرس الثورى تنظيم حزي الله: وأهدافة حماية منجزات الثورة والدفاع عن ولاية الفقية المطقة ومحارية الغزو الثقافى الغربى ولهذا الحزب دور فاعل و مؤثر فى العلاقات الخارجية الإيرانية ثانيا: المملكة العربية السعودية: الموقع: والمســاحة وتثــل_2250000 كموطول الحدود البرية 4531كم2_وتحتل السـعودية موقعا إستراتجيا وتتنوع تضاريس المملكة نظرا لإتساع مساحتها

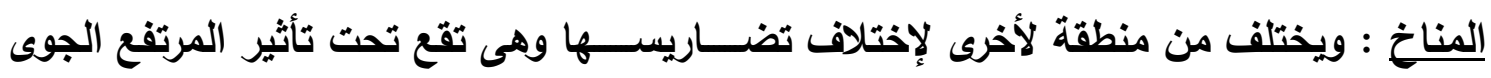

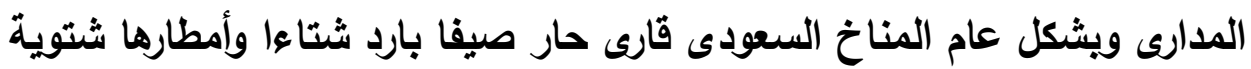

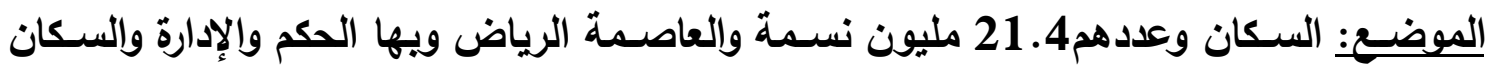

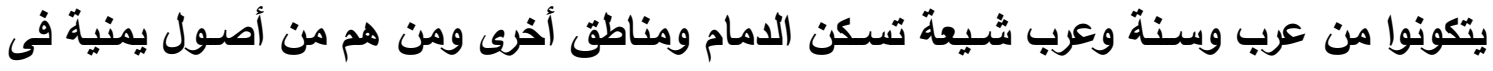
الجنوب ويسكنون الحجاز وعسير ونجران والبدون الموارد: البترول وهو المصدر الأساسى للبلاد

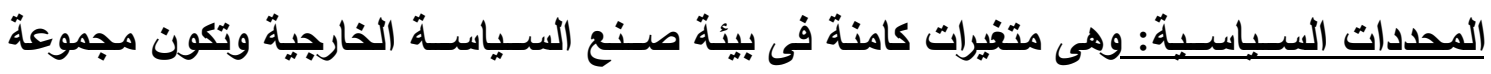

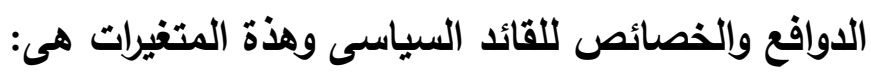
دورالقِّادة الحاكمة: نظام الحكم السعودى ينحصر فى أبناء الملك المؤسس عبد العزيز آل سعود

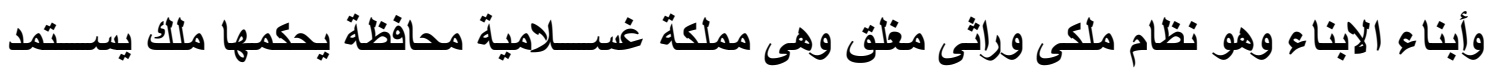
سلطتة من ولاء عائلتة آل سعود كنلك رجال الدين وهناك عدة مستويات: المستوى الاول ويختص بة الملك وولى العهل ويختار من قبل الملك وفى الك

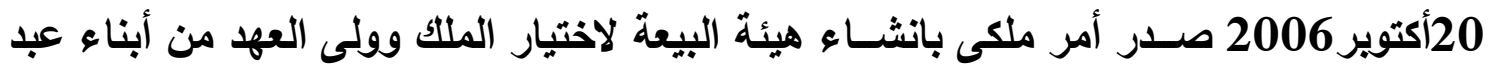


العزيز آل سعود وفى 10 أكتوير 2007 أعلن عن تثكيل هذة الهيئة وتضم 35 عضوا من أبناء العائلة المالكة.

المســـتوى الثانى: ويختص بة مجلس الوزراء ويناقش نتائج التى وصــلـل لها وزير الخارجية

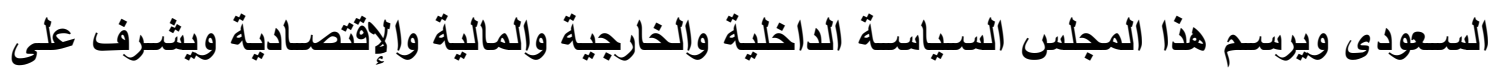
تنفيذها

المستوى الثالث: مجلس الأمن القومى وهو هيئة إستشــارية عليا ويتولى رسم وتنفيذ السياسـة

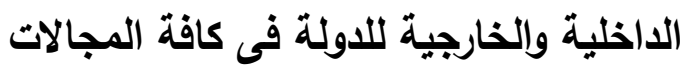

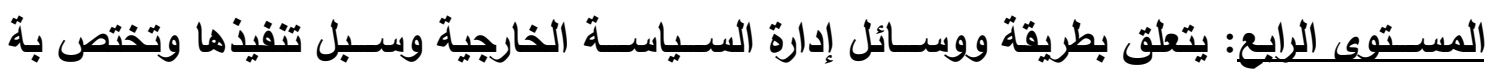
الخارجية وأجهزتها المسـتوى الخامس: يتعلق بمجلس الثـورى الذى أنثـئ 1992 ويمارس المهام المناط بهاه وفقا

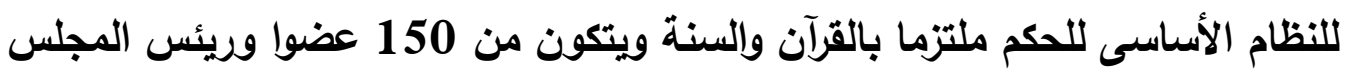

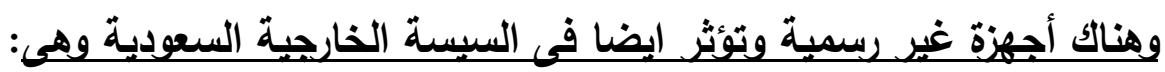
أعضاء الأسرة الحاكمة: وأعضائها 7000 أمير ومنخرطين فى المجالات السياسية والعسكرية والإقتصادية ولههم تأثيرهم فى القرار السياسى الأسى علماء الدبن : فالحكم فى السعودية هو كيان عملى نتج صمودة من قوة سلطة النفط والعمل فى العى المستوى الا|خلى والخارجى وإعتمادة على القوة الدينية

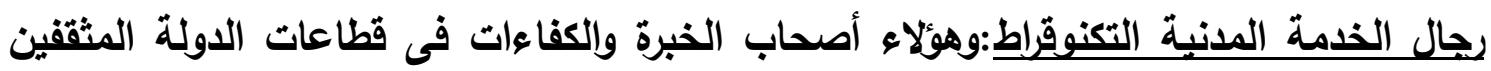
وأساتذة الجامعات: ودورهم كيفية تثكيل التوجة العام وهم مستثارين فى أجهزة الدولة ورجال

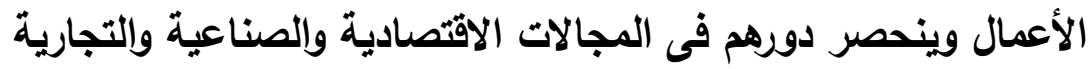
رجال الاعلام والصـحافة: ويقومون بدور مسـاند للحكومة داخليا وخارجيا والتأثير فى الرأى العام وقناة اتصال بين المواطنين وصانعى القرار أثر تغيرلقيادة السعودبية الابيرنية : التغيرفى القيادة السعودية: تجد السعودية نفسها اليوم فى موقع القلب من المسائل الحاسمة والأزمات التى تواجة منطقة الشرق الاوسط والعالم الاسلامى والنظام العالمى ويعد تأسيس الاولة السعودية الثالثة 1902 ، ومع ظهور البترول اتجهت المملكة لعقد اتفاقية التعاون والاستثمار مع الولايات المتحدة وغيرها. ويانتهاء عهر السبعينات من القرن الماضى أوجلت المملكة دولة الجئة

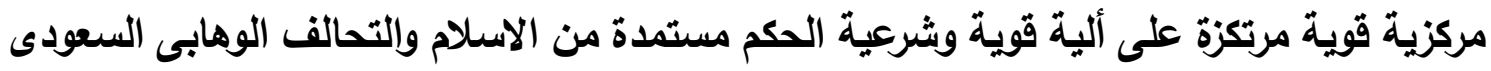
أساس السلفية المعاصرة وهذا النموزج انسحب على بلان عربية عرية عدة ، ثم حدوث حرب الظليج 
الاولى والثانية واستثاءث القوات الاجنبية للمنطقة وللاأراضى السعودية ثم حدوث هجمات 11سبتمبر 2001 وتورط سعودين فيها وتلاها الحرب على الارهاب ويقيادة أمريكية ونتج

عنها غزو أفغانستان والعرلق ومن تداعيات. الههوامش:

1) عصسام السيد عبدالحميد، العلاقات السعودية - الإيرانية، 1982 - 1997، القاهرة : عين

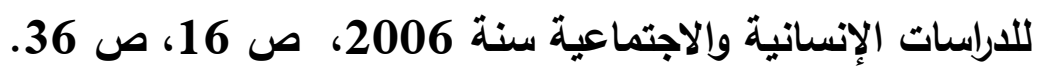

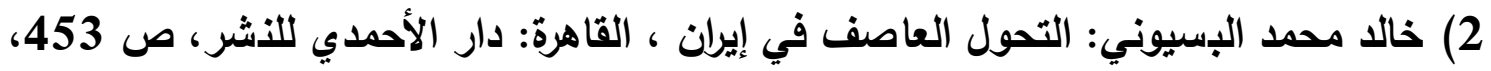
.454

3) محمد على تسخيري ، حول الدستور الإيراني، ص 21 ، طهان المجمع العلمي للتقريب بين

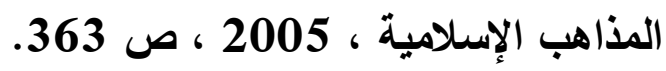

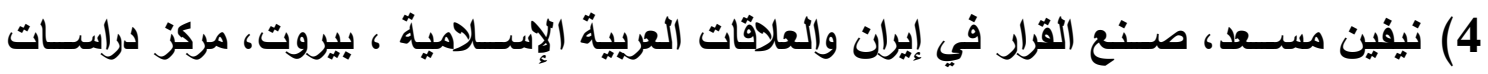

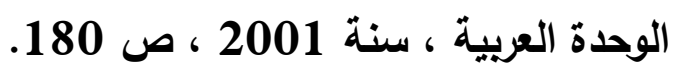

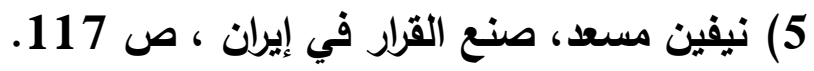

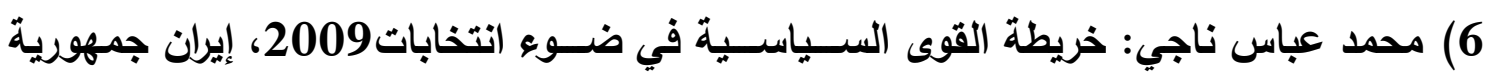

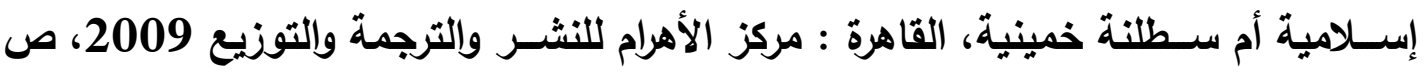

7) المرجع السابق ، ص 157.

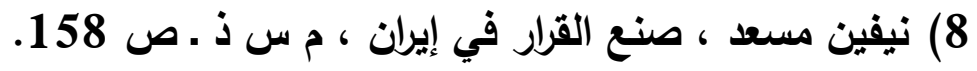

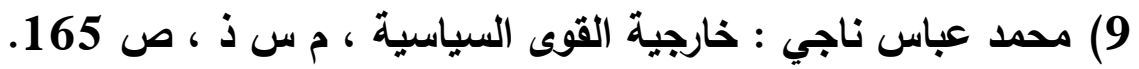

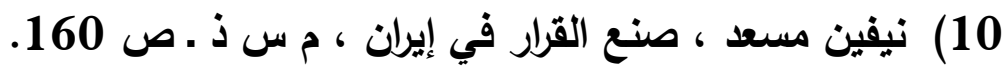

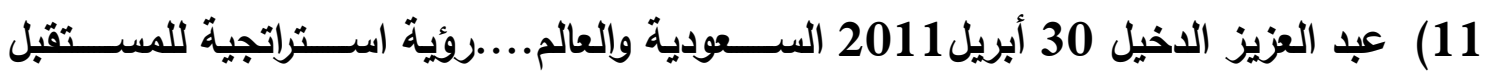
الاقتصاد والبترول.

12) التقرير الاســتراتيجي الخليجي 2006 - 2007م ، مجلس التعاون الخليجي2006 -

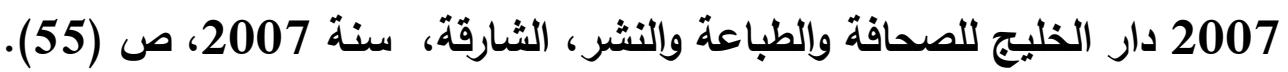
13) المادة 19 من نظام مجلس الوزراء السعودي في 4 فبراير 2007 2010م.

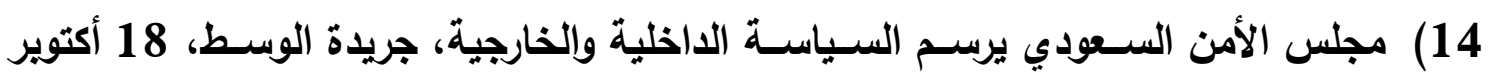
2005 مجلس الثورى في 6 فبراير 2010م. 
16) تنم نيبلوك، المملكة العربية الســودية، والســلطة الثــرعية، مركز الخليج للأبحاث، أبو

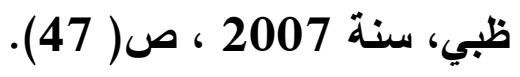

17) مضــاوي الرثـيد، مسـألة الدولة السـعودية أصسوات إســلامية من الجيل الجديد، مشـلين

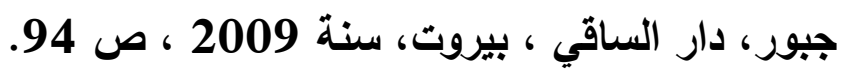

18) صـالح المانع، البعدالأيديولوجي في العلاقات السـعودية الإيرانية، في جمال سنـاند السـويدي

$$
\begin{aligned}
& \text { (محرر) إيران والخليج البحث عن الاستقرار، ص صد } 223 . \\
& \text { 19) تيم نيلوك ، مرجع سابق ذكره ، ص } 69 .
\end{aligned}
$$

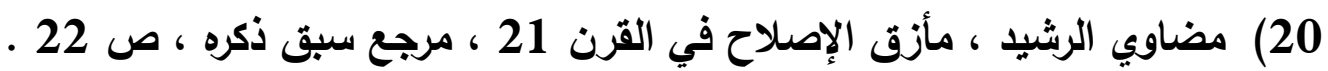

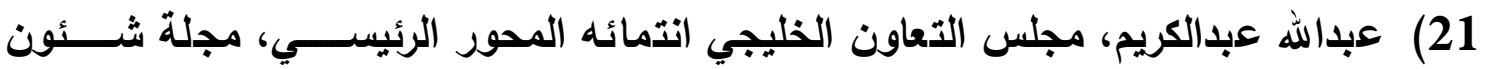

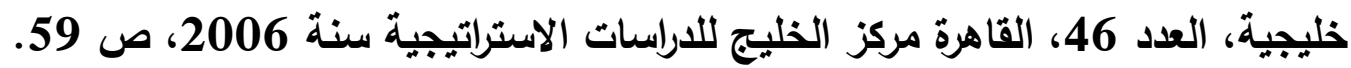

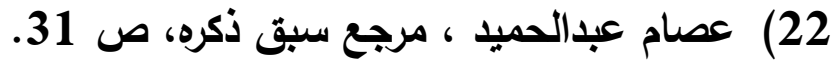

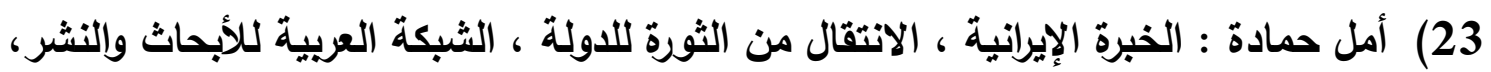

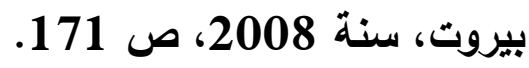

24) محمد السعيد إدريس، أحمد منيسي: "الاتجاهات الرئاسية الإيرانية"، كراسـات استراتيجية،

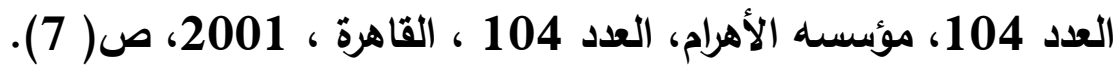
25) محمد السعيد إدريس: السـياسـة الأمريكية في منطقة الثـرق الأوسط أولق الثـرق الأوسط،

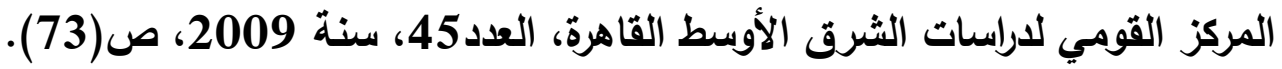

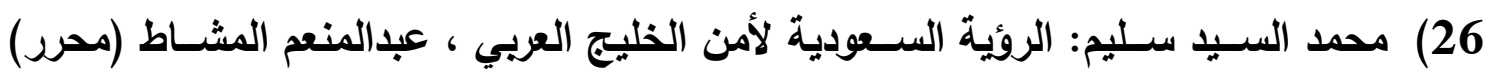

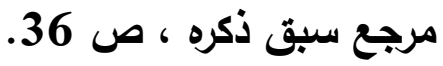
27) على الدين هلال : أزمة الخليج وتداعياتها على الوطن العربي ، مركز دراســـات الوحدة

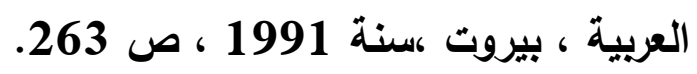

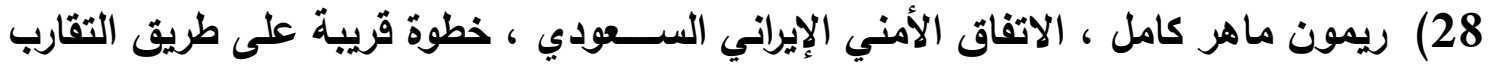

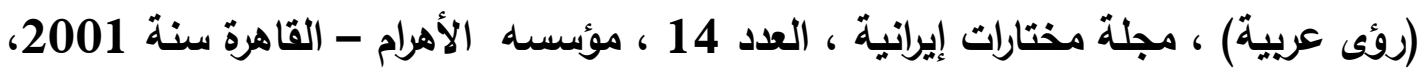
ص 53 - 57 ( 59

29) حاتم عليان محمد الحازمي: السياسـة السعودية تجاه أمن الظليج من 1990- 2000 ، 200

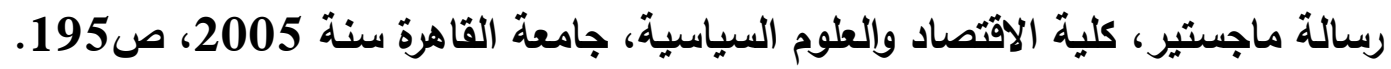

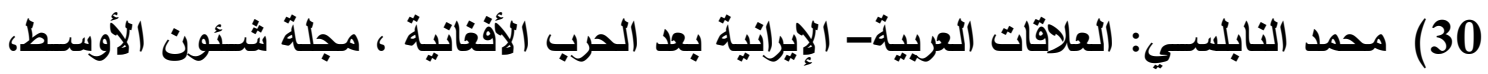
العدد 109 ، بيروت: مركز الاراسات الاستراتيجية، سنة 2003 ، ص 185. 
31) على الدين هلال / الإثــــاليات في العلاقات الإيرانية ، (مؤتمر) القاهرة : المركز الدولي

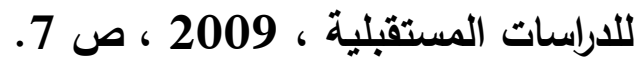

32) نيفين مسعد: الروئة الإيرانية من الظليج، عبد المنعم المشـاط (محرر)، مرجع سبق ذكره،

$$
\text { ص } 309 \text { - } 327 .
$$

33) علا عبدالعزيز أبو زيــ ، التطور اليراني لأمن الظليج بعد حرب الخليج الثـانيـة في:

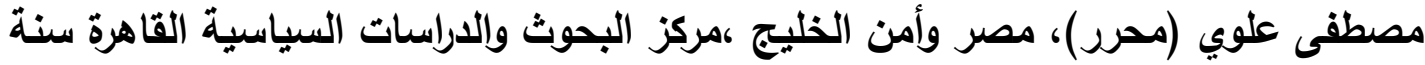

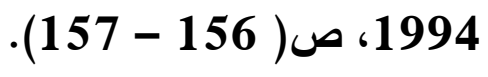

34) رمضـان كيليش، بنية الأمن في الخليج العربي بعد الحرب الباردة، مجلة شـئون الأوسـط،

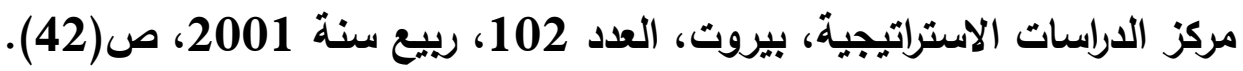

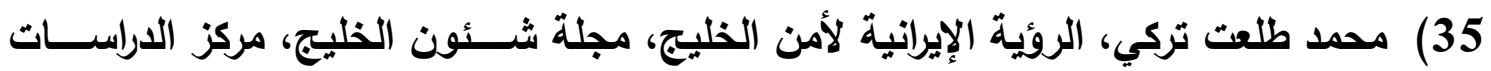

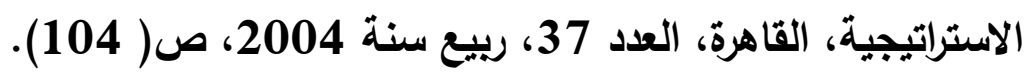

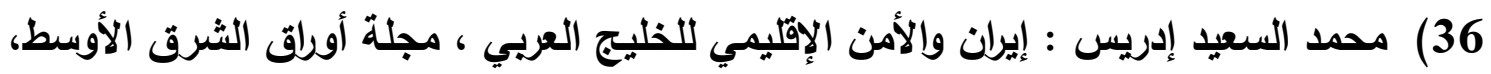
المركز القومي لدراسات الثرق الأوسط، القاهرة ،العدد 38، سنة 2007 ، ص( 16 16). 37) محمد عباس ناجي، حصـاد مشـاركة نجاد في قمة مجلس التعاون، مجلة مختارات إيرانية،

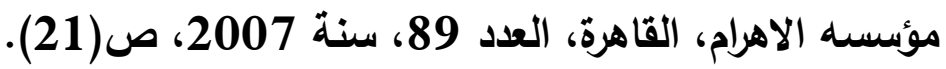
38) مالدين أو لبرايت، الجبروت والجبار تأملات في السـلطة والعنف والثـئون الدولية، ترجمة:

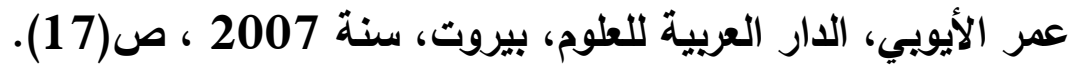
39) التقرير الاستراتجي العربي، سـنة 2002 - 2003 الأزمة العراقية الأمريكية الاتجاه نحو صلئه الحرب، مؤسسة الأهرام، صد 29.

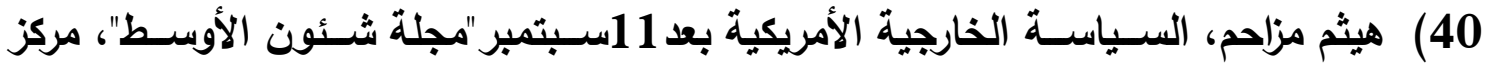

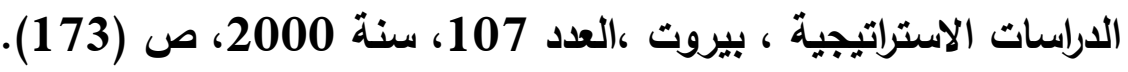

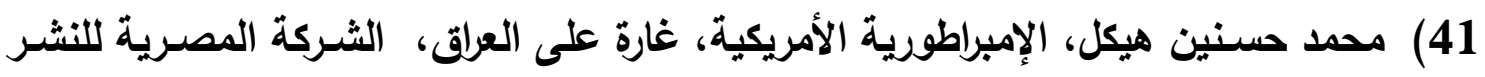

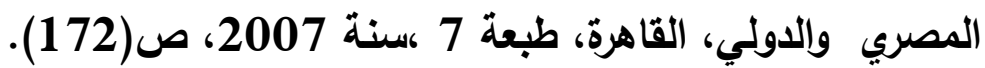

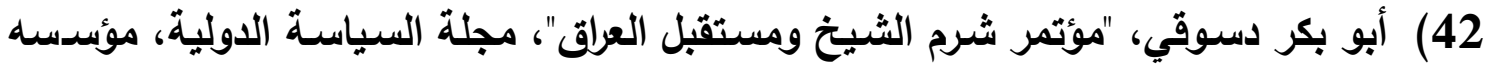

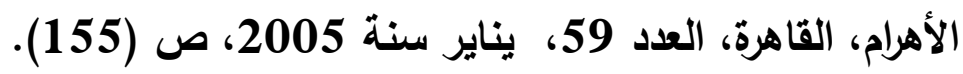

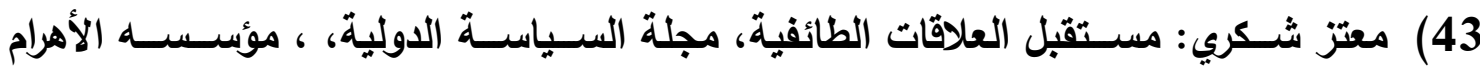

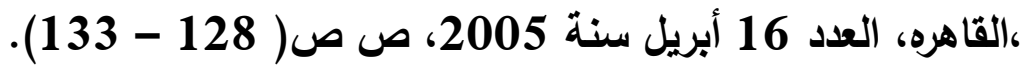


44) خريطة طريق أمريكية للشرق الأوسط، مجلة مختارات إيرانية، مؤسسـه الأهرام ، القاهرة،

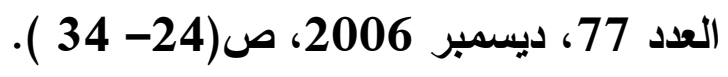

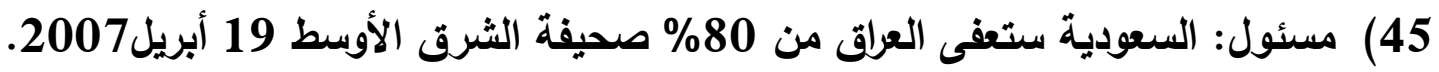

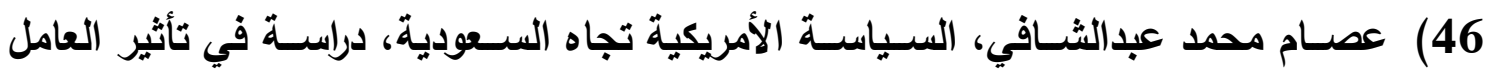
الايني ، ســنة 2001 - 2005، رســالة دكتوراة غير منثــورة ، كلية الاقتصــاد والعلوم

$$
\text { السياسية ، جامعة القاهرة ، } 2009 \text { ، ص (342 - } 345 \text { - } 340 \text { ) ). }
$$

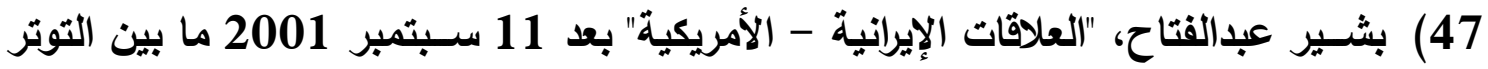
الظاهر والتقارب الذفي مجلة شـئون خليجية، مركز الخليج للاراسـات الاستراتيجية ، القاهرة

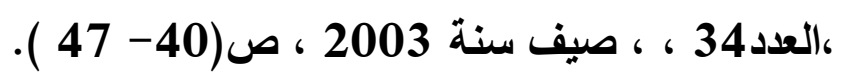

48) طلال عتريس، إيران إلى أين، مجلة المســتقبل العربي، مركز دراســـات الوحدة العربية،

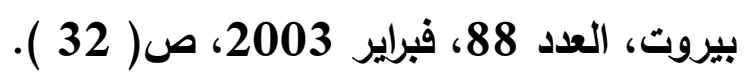

49) محمد السعيد إدريس، إيران والأمن الإقليمي للخليج العربي، أولق الثرايز الثرق الأوسط، المركز

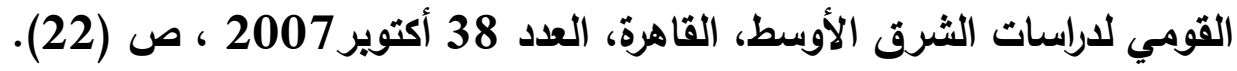

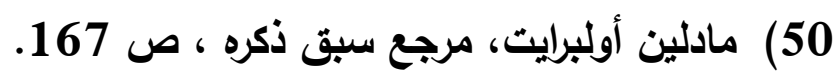

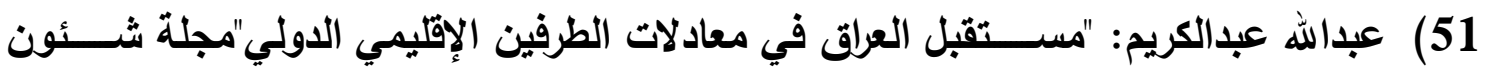
خليجية مركز الخليج للاراسات الاستراتيجية، القاهرة، العدد53، ربيع 2008، ص204. 52) خليل العناني: النفوذ الإيراني في العرلق، مجلة السياسة الدولية، مؤسسة الأهرام ، القاهرة، صلئ

$$
\text { العدد 115، سنة } 2006 \text { ، } 2006 \text { ، ص } 126 .
$$

53) نيفين عبدالمنعم مســــ: الإطار الإقليمي، حالة الأمة العربية 2008 ،ن 2008- 2009 أمة في خطر، مركز دراسات الوحدة العربية، بيروت، سنة 2009، ص 56 ـ 54) نيفين عبدالمنعم مسعد : نفس المرجع السابق ، ص 56.

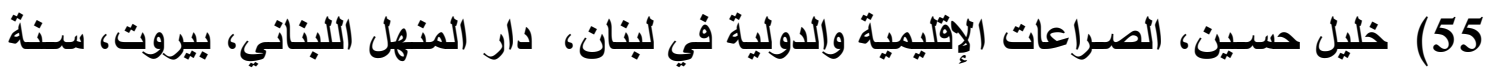

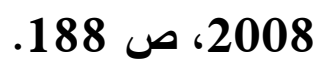
56) خليل العناني، الموقف السعودي من الحرب (مؤتمر)، تداعيات الحرب الإسرائيلية اللبنانية

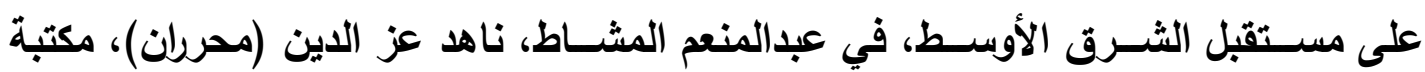
الثروق الاولية، القاهرة، 2008 ، ص 516. 57) حســن أبو طالب، البيئة الإقليمية، (مؤتمر) تداعيات الحرب اللبنانية الإســــائيلية على مستقبل الثرق الأوسط) مرجع سابق، ص 95 
58) سامـح راشد، إيران وسوريا التحالف حول لبنان ، مجلة السياسة الدولية، مؤسسة الأهرام، القاهرة، العدد 166، سنة 2006، ص 135.

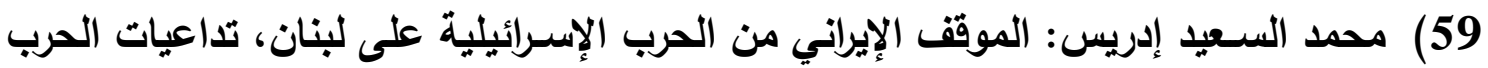
الإسرائيلية اللبنانية، مرجع سبق ذكره ، ص 591.

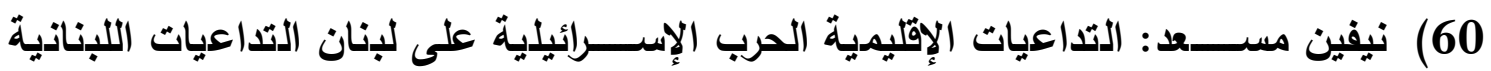
والإسرائيلية وتأثيراتها العربية والأمريكية والدولية، مركز دراسات الوحدة العربية، بيروت، سنة الإنة 2006، ص 309.

61) التقرير الاســـتراتجي العربي32007 - 2008، النظام الإقليمي العربي، الأزمة اللبنانية،

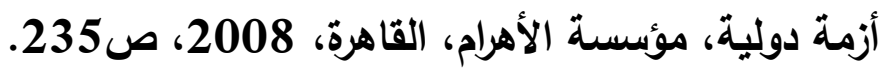

$$
\text { 62) مرجع سبق ذكره ، ص } 239 \text { - } 240
$$

63) نيفين مسـد: حالة الأمة العربية 2008 - 2009 أمة في خطر : أحمد يوسـف أحمد ، نيفين مسعد (محرين)، مركز دراسات الوحدة العربية، بيروت، سنة 2009، ص ص صلاسله $58-$

64) عماد جادن القضية الأفغانية وانعكاساتها ، مرجع سبق ذكره ، ص 182 ، 185

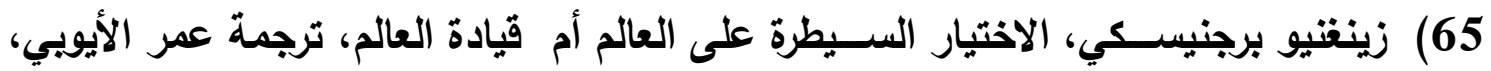

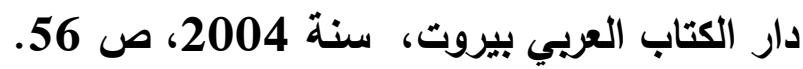
66) المرجع السابق، ص 121. 67) مرجع سابق ذكره، ص 86

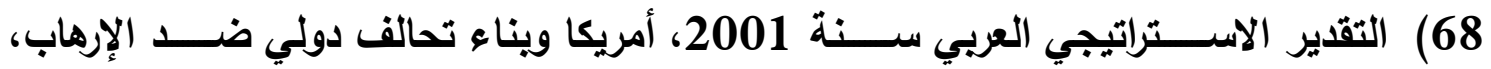
التقاعلات الدولية، مؤسسة الأهرام، القاهرة، صـ 62. 69) محمد سعيد عبدالمؤمن: إيران وجاراتها والأزمات الإقليمية، سلسلة ترجمات، الأرام، المركز الدولي للاراسات المستقبلية والاستراتيجية، القاهرة، العدد

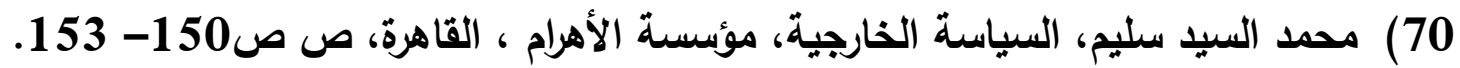

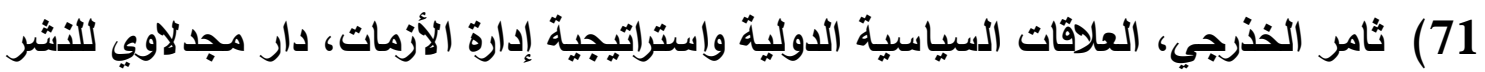

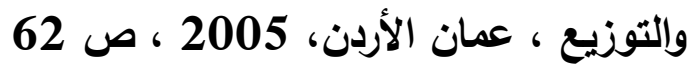

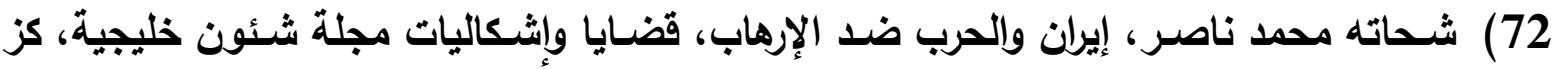
الخليج للاراسات الاستراتيجية، القاهرة، العدد29، ربيع سنة صند الإرهاب، 2002، ص107. 
73) فوزي دروثي، النفوذ الإيراني في الثـــرق الأوســـ والعراق وأفغانســان، مجلة مختارات

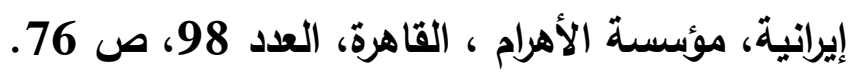

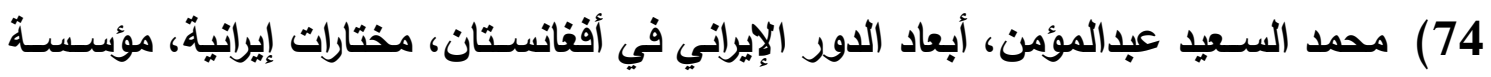

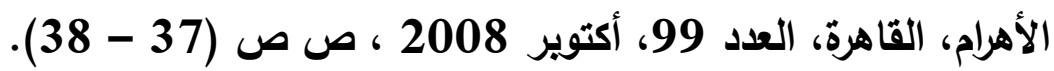
75) محمد النابلسي، العلاقات العربية الإيرانية بعد الحرب الأفغانية، مجلة شئون الأوسط، مركز الدراسات الاستراتيجية، العدد 109 ، بيروت، 2003 ، ص 186. 


\section{المراجع الأجنيية}

1) https://www.aljazeera.net/specialfiles/pages/b084e994-6664-473b9f94- 20aeb4796f94

2) http://www.alarabiya.net/articles/2011/01/11/133059.html.

3) http://www.moqatel.com/openshare/behoth/dwalmodn1/iran/03iran.jpg cvt.htm

4) Report of the word social situation(2009),word development indicators, $1 \mathrm{mf}$ world economic outlook(2011) (2012).

5) world economic outlook(2010,2011,2012)-direction of trade statistics international monetary fund, quarterly, September (2012).

6) http://www.arab.jpu.org/pdf/related.tcosgunspram,asp? sprame

7) http://www.aleqt.com/2011/04/30/article532838.html

8) http://www.shura.gov.sa/wps/wcw/connect/shuraurabic/internet/publica tion/FAO 